\title{
OS GRANDES CLIMACES DO BRASIL. II - Considerações gerais sôbre a vegetação da região amazônica *
}

\author{
HENRIQUE P. VELOSO \\ Instituto Oswaldo Cruz, Rio de Janeiro, Guanabara \\ (Com uma figura no texto)
}

O presente trabalho, segundo da série sôbre a vegetação brasileira (54c), representa uma síntese dos atuais conhecimentos geográficos e botânicos sôbre a região amazônica. Região descrita em 1745 por CoNDAMine (14), foi estudada por Spix \& Martius (47a e 47b), Wallace (55), Bates (6), SPRUCE (48), etc., que, no século XIX, imprimiram as bases de sua geografia. Contudo, só recentemente, após soluções de problemas correlatos, o assunto pôde ser considerado em detalhe, assim: com o trabalho de Galvão (21), após os estudos climáticos de CoINTE (13), Serra \& Ratisbonna (44a e 44b) e Schmitd (42), foi o clima devidamente enquadrado nos tipos de KoEPPEN (28); com as investigações geomorfológicas de BARbosa (5), contestando a teoria de Derby (15) quanto à formação do rio Amazonas -, tornam válidas certas especulações paleoclimáticas (2b e 54a); e, finalmente, as pesquisas fitossociológicas de TAKeUchi (50a, 50b e 50c) e RodRIGUES (39), as observações botânicas de Ule (53a e 53b), Huber (24a e 24b) e Massart (33), e os estudos fitogeográficos de DUCKe \& BLACK (16), nos permite discutir a questão com alguma segurança.

Não podiamos deixar de destacar os trabalhos geográficos de GuERRA (23d, 23e, 23g e 23h) e o magnífico estudo botânico de SchNell (43) que, com base realmente científica, esclarece, discute e equaciona muitos dos problemas ligados à Amazônia.

\section{SINTESE FITOGEOGRÁFICA}

A região amazônica brasileira (46), onde se encontram as mais variadas condições ecológicas, pode ser descrita como formada por dois

* Recebido para publicação a 2 de janeiro de 1962 .

Trabalho do Instituto Oswaldo Cruz, realizado sob os auspícios do Conselho Nacional de Pesquisas. 
planos arenosos de "baixos platôs terciários" (2a e 35) ligeiramente inclinados, cuja junção, na direção geral leste-oeste, corresponde à planície quaternária recente. Planura, às vêzes interrompida por elevações isoladas, estende-se, a partir do sopé dos Andes, entre dois planaltos cristalinos, - o escudo guianense, ao norte, e o "escudo bóreobrásilia" (11), ao sul.

A Amazônia, quanto ao seu clima, com temperaturas sempre elevadas e, em geral, com chuvas abundantes, pela variação da precipitação anual, pode ser dividida em três zonas principais, onde as nuanças climáticas possibilitam uma série de sub-divisões (21). A primeira grande zona, circunscrita ao alto rio Negro e porção oeste do Solimões, é caracterizada por elevadas e bem distribuídas precipitações (Af). A segunda, predominando na maior parte da região, caracteriza-se por longa estação chuvosa e um período de baixas precipitações $(\mathrm{Am})$. E a terceira, com chuvas torrenciais num curto período, moderadas em outro e uma nítida estação sêca (Aw), predomina sobretudo em faixas: a do norte, no alto rio Branco, desce fazendo uma leve curvatura até o rio Maicuru de onde sobe novamente, em reta, para a Guiana Inglesa; e, a do sul, formando um semi-círculo, sai da foz do Turiaçu no Maranhão, desce em linha reta para Goiás e daí, na direção leste-oeste. penetra no Território de Rondônia, pela chapada dos Parecis.

Respondem, aparentemente, a êsses tipos físicos outras tantas formações vegetais, - floresta aberta (Af), floresta densa (Am) e savana (Aw) que, entretanto, se entrelaçam num emaranhado de núcleos esparsos. Assim, a densa floresta higrófila, dominante na região, existe nas margens dos rios e nas várias depressões úmidas da Amazônia; a savana, dominante em grandes áreas dos planaltos, pode ser encontrada ilhada pela mata e existe em extensa faixa litorânea do Amapá e Marajó; e, finalmente, a formação florestal mais aberta que domina no alto rio Negro, é encontrada nos morrotes e outeiros dentro da região amazônica. Duas outras formações completam, a grosso modo, o quadro fitofisionômico - campo e manguezal. O campo, ocupando as margens dos grandes rios, dá à zona inundada periòdicamente uma característica de áreas de várzea - campos de aluvião recente (45) intercalados aos igapós - matas permanentemente inundadas $(24 \mathrm{~b}$ e 35). O manguezal que, em certas áreas acompanha o curso dos rios, principalmente as do Território do Amapá, vive sempre em ambiente salobro (24a e 24b). Podemos, assim, levantar a questão da existência de formas de vegetação que possìvelmente refletem uma situação atual e outras, ilhadas ou não, que possibilitam várias interpretações.

Com êstes preliminares ecológicos e com base nos mapeamentos mais recentes $(16,20,29$ e 46), resolvemos tentar uma nova divisão fitogeográfica da Amazônia, onde os conhecimentos climatológicos (21), geomorfológicos $(1,2,3,5,22,23,34,35,40$ e 49) e fitogeográficos (4. 8. $17,31,33,36,39,41,43,50$ e 52) influíram decisivamente nos limi- 
tes florísticos que, embora bastante imprecisos procuraram demarcar os tipos de vegetação com suas principais variações. Assim temos:

A - Região do EScudo GUiAnense:

1 - Sub-região do pediplano do alto rio Negro (Af). Predominância de áreas povoadas por árvores baixas, finas e espaçadas. Tipo savana.

2 - Sub-região serrana (Tm e Aw), Parima-Pacaraimã e Lua-Tumucumaque. Predominância de formações arbustivas e campestres, com florestas nas encostas suaves.

3 - Sub-região do pediplano do alto rio Branco (Aw). Predominância de savana do tipo cerrado, campos e matas ciliares com campos de inundação.

4 - Sub-região da encosta aplainada (Am e Aw). Predominância da formação florestal com raros indivíduos gigantes e ilhas de savana do tipo cerrado.

5 - Sub-região do pediplano do Amapá (Am). Predominância da formação florestal do tipo médio.

B - REgiÃo SEDIMENTAR:

1 - Sub-região considerada terciária (Am):

a) Áreas dos baixos platôs arenosos. Predominância da formação florestal, povoada por elementos gigantes $\mathrm{e}$ com ilhas de savana do tipo cerrado.

b) Áreas da superfície aplainada do Acre. Predominância da formação florestal, com elementos gigantes.

2 - Sub-região quaternária antiga $(\mathrm{Am})$. Predominância da formação florestal densamente povoada por elementos gigantes.

3 - Sub-região quaternária mais recente (Am):

a) Áreas da orla marítima. Predominância da formação do tipo manguezal.

b) Áreas da planície do Amapá e Marajó. Predominância da savana do tipo cerrado, com grandes extensões de campos inundáveis.

c) Áreas da planície inundável do baixo Amazonas. Predominância da formação florestal do tipo igapó, com agrupamentos palmatifoliados.

d) Áreas da planície inundável do médio Amazonas. Predominância da formação florestal do tipo igapó e grandes extensões de campos de várzea.

C - REGIÃO DO ESCUDO BóREO-BRASÍlia:

1 - Sub-região do planalto sul-amazonense:

a) Areas da chapada cretácea (Aw). Predominância da savana do tipo cerrado. 
b) Áreas da encosta aplainada (Am). Predominância da formação florestal, com elementos gigantes.

2 - Sub-região do planalto maranhense:

a) Áreas da chapada cretácea (Aw). Predominância da savana do tipo cerrado.

b) Áreas da superfície aplainada (Aw). Predominância da formação florestal do tipo palmatifoliado.

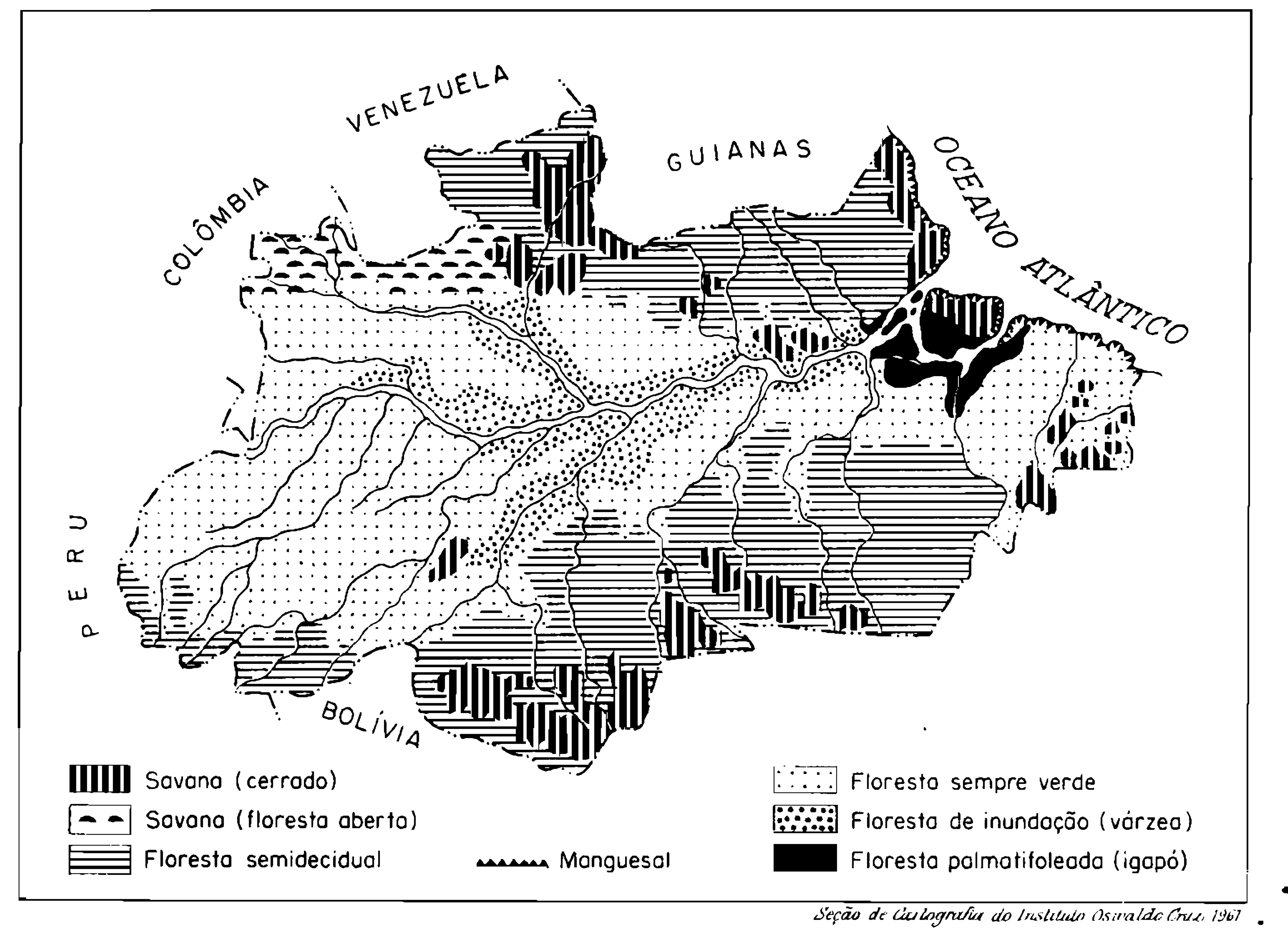

Fig. 1 - Mapa fitogeográfico da regiáo amazônica.

Vemos, assim, que a grande região norte (46) contém os tipos de vegetação do Brasil (54c), compreendidos dentro de um clima relativamente uniforme (quente e úmido), onde a ação das masas de ar (44a e 44b), aliadas à enorme variação topográfica e às nuanças do solo, em função de sua origem geológica, refletem possivelmente as diferenças florísticas que se observam.

\section{ORIGEM DAS FORMAS DE VEGETAÇÃO (Discussão)}

Podemos, com êste quadro fitogeográfico elementar, iniciar uma apreciação sôbre as possíveis expansões dos tipos de vegetação em face das teorias geomorfológicas. Nada de positivo, entretanto, se pode afir- 
mar sôbre as flutuações climáticas mais recentes responsáveis ou não por passadas coberturas vegetais, sem um melhor conhecimento da idade dos vários tipos de concreções lateríticas (43) e sem um estudo detalhado nas camadas polínicas das turfeiras locais (54c) .

A hipótese clássica de DeRBY (15) para explicar a origem da bacia amazônica, posteriormente desenvolvida por KATZER (27) e aceita pela maioria dos geólogos até 1958 (23h), permite um esclarecimento, não muito convincente, para os núcleos de savana encontrados nos sedimentos arenosos do terciário. Assim, a teoria sôbre a mudança de drenagem de oeste para leste, pelo soerguimento dos Andes, indicaria que houve um caminhamento da vegetação, a partir do pleistoceno, em terrenos antes ocupados por lagos interiores. A vegetação florestal, assim sendo, - partindo do conceito de que as espécies sempre tiveram o mesmo comportamento em relação ao ambiente que se conhece atualmente (38a) - , expandiu-se em solos bastante úmidos e despovoados. Porém, quanto à savana, temos de admitir um possível rebaixamento do lençol freático para explicar a sua ocupação pois, sendo uma vegetação composta de espécies com raízes profundas e reações higrófilas ( $38 \mathrm{~b}$ e $38 \mathrm{c})$, sòmente uma forte drenagem que, num tempo relativamente longo, isolou os atuais testemunhos arenosos (32), explicaria razoàvelmente, em face a esta teoria, a existência de modernos núcleos de savana em relação a uma floresta mais antiga que os envolvem, onde teríamos de aceitar a improvável formação de concreções lateríticas sob cobertura florestal (23b). Contudo, para que isso se passasse, seria necessário admitir-se a pré-existência no período terciário dos mesmos grupos florísticos nos escudos cristalinos (12) ou, então, pelo menos, se aceitar expansões recentes de refúgios sobreviventes de passadas flutuações climáticas (26). Também o homem, evidentemente, pela ação continuada do fogo, pode ser responsabilizado pela alteração e ampliação dessas áreas (36) mas, provàvelmente, nunca ser o causador da savana na Amazônia.

A hipótese climática de BARBosa (5) para explicar a origem do rio Amazonas, muito bem discutida por GuERRA (23h), vem de encontro à teoria de Veloso (54a) e proporciona maior validade à especulação de AB'SABER (2b) .

E muito difícil ou mesmo impossível, com os atuais conhecimentos, criticar-se qualquer destas hipóteses; contudo, a teoria da mudança climática como possível ocasionadora de modificações no tipo de drenagem - de endo- para exorréica - , como explicação básica da formação do rio Amazonas, altera radicalmente a idéia que se podia fazer sôbre a região porque, forçosamente, um clima do tipo senegalês de grande extensão (2b) ocasionaria vasto revestimento florístico próprio de áreas mais sêcas, o que pode ser provável em vista de relíquias arbóreas desta flora persistirem associadas com famílias xerófilas das caatingas nordestinas - Cactaceae - e higrófilas do cerrado - Dilleniaceae - com gêneros americanos de larga dispersão e exclusivos das áreas dessecadas, atualmente com estiagem. No entanto, a demonstração de que os sedimentos ditos terciários provém de áreas cir- 
cunvizinhas, inclusive da andina (5), aliada a alguns subsídios geomorfológicos - existência de vários níveis de terraços (22), crosta laterítica dos baixos platôs arenosos (2b), movimentos tetônicos antigos (34) e vulcanismo recente (37) - possibilita uma outra interpretação, também razoável, para as expansões e regressões florísticas (54b). Assim, em época mais recente, o terreno sofrendo erosão e sedimentação locais, apontadas pelas prováveis variações do nível de base (7), foi aos poucos restringindo os maiores núcleos de savana aos escudos cristalinos, onde persistem os vestígios da intensa dessecação do passado inselberge e aplainamentos da encosta guianense (23h) -; enquanto os fragmentos destas concentrações, quando localizados no meio da floresta, indicariam possíveis regressões, e quando instalados em solos quaternários, ao longo da costa marítima do Amapá e Marajó, representariam expansões mais modernas (30).

\section{CONSIDERAÇÕES GERAIS}

Podemos, como subsídio às apreciações acima, tentar analizar a vegetação pela atual distribuição dos gêneros de larga dispersão (10) e pela identidade mundial das formas ecológicas em comunidades fitofisionômicas semelhantes mas genèricamente diferentes (43), em face aos sistemas filogenéticos mais modernos (18, 25 e 51). Assim, a constatação de GyMNOSPERMAE em áreas restritas dos planaltos que circundam a bacia amazônica - Zamia (Cycadaceae), Gnetum (Gnetaceae) e Podocarpus (Podocarpaceae) - aliadas às ANgyospermae arbóreas - Talauma (Magnoliaceae), Curatella (Dilleniaceae), etc. revelam a existência de relíquias com reações fisiológicas divergentes. Com esta revelação pois, enquanto as espécies dos gêneros americanos Zamia e Curatella têm características xerófilas (19a e 19b) e as dos gêneros cosmopolitas Podocarpus, Gnetum e Talauma têm higrófilas (19a e 19b), fica demonstrado que as áreas intensamente erodidas e lixiviadas sempre existiram ao lado das de deposição e mais úmidas (9). A complexa vegetação arbórea atual, assim, é o reflexo dêste intenso dinamismo porque, sòmente, as famílias de grande dispersão são exclusivas - Magnoliaceae e Lauraceae nas florestas e Dilleniaceae e Kielmeyera ${ }^{1}$ nas savanas.

Compreender-se-á, dêste modo, a atual distribuição arbórea regional pois, a aparente indiferença aos habitats pelas famílias consideradas mais evoluídas - Vochysiaceae (Vochysia e Qualea) —, esclarece

O gênero Kielmeyera Mart. exclusivo de áreas americanas dessecadas com estiagem, incluído por ENGLER-PrantL nas Guttiferae (19a) e por Hutchinson nas Bonnetiaceae (25), é por nós considerado como um grupo à parte. Sua posição sistemática intermediária, entre Dilleniaceae (de dispersão geográfica mundial), Caryocaraceae (exclusiva das Américas), etc., indica provàvelmente a existência de uma série filogenética americana sem ligação direta com as Guttiferae que se originaram do grupo THEales. 
uma seleção de condições ecológicas relativamente recentes que são menos freqüientes nas famílias tidas como mais primitivas, observando-se, entretanto, nestas últimas, readaptações ecológicas modernas - Leguminosae (Bowdichia e Stryphnodendron com fôlhas decíduas mesmo quando nas florestas), Annonaceae (Annona e Xylopia com fôlhas perenes mesmo quando nas savanas), etc. Isto, evidentemente, não quer dizer que não existam famílias mais evoluídas com gêneros exclusivos - Vochysiaceae (Salvertia nas savanas e Erisma nas florestas).

Não podemos, é claro, deixar de considerar que a dominância de famílias, gêneros ou espécies, além das limitações genéticas, subordina-se a uma seleção de condições ecológicas. Assim, a grande dominância de Leguminosae e Vochysiaceae nas savanas e florestas da Amazônia, esta última bem mais evoluida do que a primeira, indica que a fácil dispersão aérea de seus frutos ou sementes deve ser o fator responsável pela grande seleção de formas, espécies e, possìvelmente, gêneros aí existentes; assim como, a maior resistência dos frutos ao transporte aquático deve ter condicionado a concentração de indivíduos de Palmae nas florestas à margem dos rios e dos igapós.

\section{CONCLUSÕES}

O que existe atualmente na Amazônia são 4 grandes faixas arbóreas endêmicas que refletm outras tantas situações ecológicas, provàvelmente, correspondentes à evolução da rêde hidrográfica:

1. Nas áreas dessecadas dos planaltos cristalinos.

A. No alto rio Negro (Af), com espécies florestais espaçadas e baixas, dominada pela Leguminosae (Aldina sp.). Formação do tipo savana.

B. No alto rio Branco e na chapada sul-amazônica (Aw), com espécies do cerrado, dominada pelas Vochysiaceae ( $\mathrm{Sal}$ vertia), Dilleniaceae (Curatella), Kielmeyera, etc. Formação do tipo savana.

2. Nas áreas que circundam a região sedimentar (Am), desde o escudo guianense, passando pelos Andes, até o escudo bóreobrasília, com espécies florestais deciduas Meliaceae (Swietenia) e Leguminosae (Myroxylon). Formação de florestas densas.

3. Nas áreas aplainadas dos planaltos e parte mais elevada dos platôs arenosos (Am), com espécies florestais sempre verdes onde espécies de Lauraceae, Rosaceae e Sapotaceae dominam. Formação de florestas densas.

4. Nas planícies mais ricas (Tm), com espécies florestais gigantes de Leguminosae (Cedrelinga, Dinizia, Parkia, etc.), Lecythidaceae (Bertholetia), Bombacaceae (Bombax), etc. Formação de florestas densas. 
Podemos, também, considerar as áreas instáveis com inundações periódicas - várzeas e igapós - , como a faixa representativa da atual fase evolutiva da bacia Amazônica.

\section{ZUSAMMENFASSUNG}

Um eine neue phytogeographische Einteilung des Amazonasgebietes (Região Amazônica) in Angriff nehmen zu koennen, zieht der Autor anfangs die Ergebnisse der geomorphologischen, klimatologischen und floristischen Studien aelterer und neuerer Beobachter heran und setzt sie in Uebereinstimmung mit den oekologischen Resultaten. Die Einteilung umfasst:
A. Region des guianensischen Schildes mit 5 Subregionen;
B. Region der Sedimentboeden mit 3 teilweise unterteilten Sub- regionen;
C. Region des nordbrasilianischen Schildes mit 2 unterteilten Subregionen.

In den drei Gebieten finden wir, infolge der verschiedenen geologischen Verhaeltnisse, praktisch alle Vegetationstypen Brasiliens, obwohl das Klima uniform (warm-feucht) ist.

Nach der Beurteilung der verschiedenen Theorien ueber die geologischen und floristischen Gegebenheiten und unter Hinzufuegung biologischer Tatsachen (Samenverbreitung) kommt der Autor zum Schluss, dass in dem Gebiet vier grosse, endemisch begruendete Baumzonen bestehen, deren Existenz auf dem heutigen hydrographischen Netz und seinen oekologischen Bedingungen beruht:

1. Die Trockengebiete der kristallinen Hochebenen am oberen Rio Negro und Rio Branco und auf dem suedamazonischen Schild;

2. Eine die Sedimentregion umgebende Zone;

3. Die Gebiete der Hochebenen und die hoeher gelegenen Teile der Sandaufschuettungen;

4. Die fruchtbaren Sedimentebenen.

Ausserdem kann man die wechselnden Gebiete periodischer Ueberschwemmungen als kennzeichnende Zonen der augenblicklichen Entwicklungsphase des Amazonasbeckens ansehen.

\section{REFERENCIAS BIBLIOGRÁFICAS}

1. Abreu, S. F., 1939, Observaçōes sôbre a Guiana maranhense. Rev. Bras. Geog., 1 (4) : 26-54.

2a. AB'Saber, A. N., 1956, Relêvo, estrutura e rêde hidrográfica do Brasil. Bol. Geog., 14 (132) : 226-268. 
2b. Ab'Saber, A. N., 1957, Conhecimentos sôbre as flutuaçōes climáticas do quaternário do Brasil. Bol. Soc. Bras. Geog., 6 (1) : 41-48.

3. Almeida, F. F. M., de, 1948, Reconhecimento geomôrfico nos planaltos divisores das bacias amazônica e do prata entre os meridianos $51^{\circ}$ e $56^{\circ}$ WG. Rev. Bras. Geog., 10 (3) : 65-108.

4. AUbrÉville, A., 1961, Etude écologique des principales formations végetales du Brésil et contribution a la connaissance des forêts de l'amazonie brésilienne. Centr. Techn. For. Trop., 1: 1-207.

5. Barbosa, O., 1958, Geomorfologia do Território do Rio Branco. Not. Geom.. 1 (1): $16-18$.

6. BATES, H. W., 1892, The Naturalist on the River Amazons. LXXXIX +389 pp., John Murray, London.

7. BeIGBEDER, Y., 1958, Estudo preliminar dos aplainamentos observados no alto rio Branco, entre os rios Sumurú, Cotingo e Maú. Not. Geom., 1 (1): 22-23.

8. Black, G. A., et el., 1950, Some attempts to estimate species diversity and population density of trees in Amazonian forests. Bot. Gaz., 111 (4): 413-425.

9. Cailleux, A., 1952, La géologie. Col. Que sais je?, n. ${ }^{\circ}$ 525, 128 pp., Press. Univ. de France, Paris.

10. CAMP., W. H., 1947, Distribution patterns in modern plants and the problems of ancient dispersals. Ecol. Monogr., 17 (2) : 159-183.

11. Caster, E. K., 1942, The age and correlation of Columbian devonian strata VIIIO Congr. Amer. Sci. Proceeds Washington: 27-67 pp.

12. Chaney, R. W., 1947, Tertiary centers and migration routes. Ecol. Monogr.. 17 (2) : $139-148$.

13. CoInte, P. Le, 1949, O clima amazônico (particularmente o clima do baixo Amazonas). Bol. Geog., 7 (77) : 500-508.

14. Condamine, M. De La, 1778 , Relation abrégée d'un voyage fait dans l'interieur de l'Amerique Meridionale, deruis la Côte de la Mer du sud. jusqu'aux Côtes du Brésil et de la Guyane, en descendant la riviere des Amazones. XVI + 379 pp., Jean-Edme Dufour \& Philippe Roux, France.

15. Derby, O. A., 1877, Contribuições para a Geologia da Região do Baixo Amazonas. Arch. Mus. Nac., Rio de Janeiro, 2: 77-104.

16. Ducke, A. \& Black, G. A., 1954, Notas sôbre a fitogeografia da Amazônia brasileira. Bol. Téc. Inst. Agr. Norte, 29: 1-62.

17. Egler, W. A., Contribuições ao conhecimento dos campos da Amapônia. I - Os campos do Ariramba. Bol. Mus. Paraense Emilio Goeldi, 4: $1-36$.

18. Emberger, L., 1944, Les plantes fossiles dans leurs rapports avec lee vegéteaux vivants. 492 pp., Ed. Masson \& Cia., Paris.

19a. Engler, A. \& Pranth, K., 1925, Die Natuerlichen Pflanzenfamilien, 21. IV +660 p.p., Verlag von Wilhelm Engelmann, Leipzig.

19b. Engler, A. \& Prantl, K., 1926, Die Natuerlichen Pflanzenfamilien, 13. IV + 447 pp., Verlag von Wilhelm Engelmann, Leipzig.

20. Galvão, R., 1955, Introducão ao conhecimento da área maanhense. Rez Bras. Geog., 17 (3) : 239-299.

21. Galvão, M. V., 1959, Grande região norte (Clima da Amazônia), in Geografia do Brasil, 1: 61-111, Impr. IBGE, Rio de Janeiro.

22. Gourou, P., 1949, Observações geográficas na Amazônia. Rev. Bras. Georg 11 (3) : $355-408$.

23a. Guerra, A. T., 1951, Alguns aspectos geomorfológicos do litoral amapaense. Bol. Geog., 9 (98): 167-178.

23b. Guerra, A. T., 1952, Formação de lateritos sob a floresta equatorial amazônica. Rev. Bras. Geog., 14 (4): 33-52.

23c. Guerra, A. T., 1953, Observações geográficas sôbre o Território do Guaporé. Rev. Bras. Geog., 15 (2): 3-122. 
23d. Guerra, A. T., 1954, Estudo geográfico do Território do Amapá. XIII +357 pp., Bibl. Geogr. Bras., n.o 10, Rio de Janeiro.

23e. GUERRA, A. T., 1955, Estudo geográfico do Território do Acre. 294 pp. Bibl. Geogr. Bras., n.o 11, Rio de Janeiro.

23f. Guerra, A. T., 1955, Os lateritos dos campos do Rio Branco e sua importância para a geomorfologia. Rev. Bras. Georg., 17 (2) : 220-224.

23g. Guerra, A. T., 1957, Estudo geográfico do Território do Rio Branco. 252 pp., Bibl. Geogr. Bras., n. 13 , Rio de Janeiro.

23h. GUERRA, A. T., 1959, Grande região norte (Estrutura geológica, relêvo e litoral), in Geografia do Brasil, 1: 17-60. Impr. IBGE, Rio de Janeiro.

24a. Huber, J., 1909, Matas e madeiras amazônicas. Bol. Mus. Paraense Emilio Goeldi, 6: 91-225.

24b. Huber, J., 1943, Contribuição a geografia física dos furos de Breves e da parte ocidental de Marajó. Rev. Bras. Geog., $\overline{1}$ (3) : 129-154.

25. Hutchinson, J., 1959, The families of flowering plants. XV $+792 \mathrm{pp}$. Oxford at the Clarendon Press, London.

26. Just, T., 1947, Geology and plant distribution. Ecol. Monogr., 17 (2): $125-137$.

27. KATZER, F., 1933, Geologia do Estado do Pará. Bol. Mus. Paraense Emilio Goeldi, 9: 1-240.

28. KoEpPEN, W., 1948, Climatologia. Trad. P. R. H. Péres., 478 pp., Ed. Fondo de Cultura Economica, Mexico.

29. Kuhlimann, E., 1959, Grande região norte (tipo de vegetação), in Geografia do Brasil, 1: 112-127. Impr. IBGE, Rio de Janeiro.

30. Magnanini, A., 1952, As regiões naturais do Amapá. Rev. Bras. Georg., 14 (3): 3-64.

31. Mangenot, G., 1958, Remarques sur l'Hylaea dans le Monde. An. Acad. Bras. Cien., 30 (1) : 83-90.

32. Marbut, S. F. \& Manifold, C. B., 1947, A topografia do vale do rio Amazonas. Bol. Geog., 5 (53) : 530-544. 33. Massart, J., 1930, Une Mission Biologique Belge au Brésil. Tome II, 261 pp.,
Impr. Méd. et Sci., Bruxelles.

34. MENDES, J. C., 1957, Notas sôbre a bacia sedimentar amazônica. Bol. Paulista Geog., 9 (26) : 3-49.

35. Moura, P. de, 1943, O relêvo da Amazônia. Rev. Bras. Geog., 5 (3): 3-22.

36. Pulle, A. A., 1938, Explorações botânicas de Surinam. An. 1. ${ }^{a}$ Reunião Sul-americana de Botânica, $1: 249-257$, Rio de Janeiro.

37. Ramos, J. R. A., 1958, Reconhecimento geológico no Território do Rio Branco. Not. Geom., 1 (1): 18-21.

38a. RAWITSCHER, F., 1942, Problemas de fitoecologia com consideraçōes especiais sôbre o Brasil meridional. Bol. Fac. Fil. Cie. Letr. Univ. São Paulo, 28: 5-112.

38b. Rawitscher, F. et alii, 1943, Profundidade dos solos e vegetacão em campos cerrados do Brasil meridional. An. Acad. Bras. Cien., 15 (4): 267-294.

38c. Rawitscher, F. et Rachin, H., 1946, Troncos subterrâneos de plantas brasileiras. An. Acad. Bras. Cien., 18 (4) : 261-280.

39. Rodrigues, W. A., 1961, Aspecto Phytosociologiques des pseudo-caatingas et forêts de varzea du rio Negro. Centr. Techn. For. Trop., 1: 209-265.

40. Ruellan, F., 1957, Expedições geomorfológicas no Território do Rio Branco. Inst. Nac. Pesq. Amazônia; 170 pp., Rio de Janeiro.

41a. Sampaio, A. J., 1933, A zona dos cocaes e a sua individualizacão na phytogeografia do Brasil. An. Acad. Bras. Cien., 5 (2) : 61-65.

41b. Sampaio, A. J., 1942, A flora Amazônica. Rev. Bras. Geog., 4 (2) : 313-332.

42. Schmid, J. C. J., 1942, O clima da Amazônia. Rev. Bras. Geog., 4 (3): 465-500.

43. SCHNELl, R., 1961, Le Problème des homologies phytogéographiques entre l'Afrique et l'Amerique tropicales. Mém. Mus. Nat. Hist. Nat. Bot., 12 (2): 137-242. 
44a. Serra, A. B. \& Ratisbonna, L., 1941, As ondas de frio da bacia amazônica. Bol. Geog., 3 (26): 172-206.

44b. Serra, A. B. \& Ratisbonna, L. 1942, As Massas de Ar da América do Sul. 59 pp., Impr. Serv. Meteor., MA., Rio de Janeiro.

45. Sioli, $H ., 1951$, Alguns resultados de problemas da limnologia amazônica. Bol. Téc. Inst. Agr. Norte, 24: 3-44.

46. SoARES, L. de C., 1953, Limites meridionais e orientais da área de ocorrên15 (3) floresta amazônica em território brasileiro. Rev. Bras. Geog.

47a. SpIX, J. B. \& Martius, C. F. P., 1828, Reise in Brasilien. Band. 2: 802-884. L. Leutner, Muenchen.

47b. Spix, J. B. \& Martius, C. F. P., 1831, Reise in Brasilien. Band. 3: LVI + 887 pp., F. Fleischer, Muenchen.

48. SPRUCE, R., 1908, Notes of a Botanist on the Amazon and Andes. 1: $362 \mathrm{pp}$., Mac Millan Co., London.

49. Sternberg, O. R., 1953, Sismicidade e morfologia na Amazônia brasileira. An. Acad. Bras. Cien., 25 (4): 443-453.

50a. TAKEUCHI, M., 1960, A estrutura da vegetação na Amazônia. I - A mata pluvial tropical. Bol. Mus. Paraense Emilio Goeldi, Bot., 6 : 1-17.

50b. Takeuchi, M., 1960, A estrutura da vegetação na Amazônia. II - As savanas do norte da Amazônia. Bol. Mus. Paraense Emilio Goeldi, Bot. 7: $1-14$.

50c. TAKeuchI, M., 1960, A estrutura da vegetação na Amazônia. III - A mata de campina na região do Rio Negro. Bol. Mus. Paraense Emilio Goeldi. Bot., 8: 1-13.

51. Takhtajan, A., 1959, Die evolution der Angiospermen. VIII + 344 pp. Gustav Fischer Verlag, Jena. 52. TAte, G. H. H., 1945, Notas sôbre a região do monte Roraima. Bol. Geog.,

53a. ULE, E., 1908, Die Pflanzenformationen des Amazonas-Gebietes. Bot. Jahrb., 40 (1) : 114-172.

53b. ULE, E. 1908, Die Pflanzenformationen des Amazonas-Gebietes. Bot. Jahrb., 40 (3) : 392-443.

54a. Veloso, H. P., 1946, Considerações gerais sôbre a vegetacão do Estado de Mato Grosso. I - Notas preliminares sôbre o cerrado. Mem. Inst. Oswaldo Cruz, 44 (4) : 579-603.

54b. Veloso, H. P., 1947, Considerações sôbre a vegetação do Estado de Mato Grosso. II - Notas preliminares sôbre o pantanal e zonas de transição. Mem. Inst. Oswaldo Cruz, 45 (1): 253-272.

54c. Veloso, H. P., 1962, Os grandes clímaces do Brasil. I - Considerações gerais sôbre a vegetação pa região sul brasileira. Mem. Inst. Oswaldo
Cruz, 60 .

55. WALLACE, A. R., 1911, Travels on the Amazon. VIII + 363 pp., Ward Lock \& Co. Ltd.. London. 